\title{
[ARTIGO RETRATADO] Adubação nitrogenada e qualidade fisiológica de sementes de trigo
}

Luiz Fernando Favarato ( $\left.{ }^{*}\right)$; Valterley Soares Rocha (1); Marcelo Curitiba Espindula ( ${ }^{2}$; Moacil Alves de Souza ('); Guilherme de Souza Paula (')

(1) Universidade Federal de Viçosa, Departamento de Fitotecnia, 36570-000 Viçosa (MG), Brasil.

(²) Empresa Brasileira de Pesquisa Agropecuária, Centro de Pesquisa Agroflorestal de Rondônia, BR 364, Km 5,5, 76815-800 Porto Velho (RO), Brasil.

$\left({ }^{*}\right)$ Autor correspondente: Ifavarato@yahoo.com.br

O Conselho Editorial de Bragantia decidiu, após análise, proceder à retirada formal do seguinte trabalho:

FAVARATO, L.F.; ROCHA, V.S.; ESPINDULA, M.C.; SOUZA, M.A. e PAULA, G.S. Adubação nitrogenada e qualidade fisiológica de sementes de trigo. Bragantia, 2012, doi: http://dx.doi.org/10.1590/S0006-870520 12005000009

Uma vez que foram constatados problemas com os dados apresentados. 


\title{
Adubação nitrogenada e qualidade fisiológica de sementes de trigo
}

\author{
Luiz Fernando Favarato $\left({ }^{1 *}\right)$; Valterley Soares Rocha ('); Marcelo Curitiba Espindula ( $\left.{ }^{2}\right)$; \\ Moacil Alves de Souza ('); Guilherme de Souza Paula (') \\ (') Universidade Federal de Viçosa, Departamento de Fitotecnia, 36570-000 Viçosa (MG), Brasil. \\ (2) Empresa Brasileira de Pesquisa Agropecuária, Centro de Pesquisa Agroflorestal de Rondônia, BR 364, Km 5,5, 76815-800 \\ Porto Velho (RO), Brasil. \\ (*) Autor correspondente: Ifavarato@yahoo.com.br
}

Recebido: 9/maio/2011; Aceito: 19/set./2011

\section{Resumo}

A adubação nitrogenada afeta diretamente a quantidade de proteínas presentes nas sementes, sendo um fator importante na produção de sementes com qualidade. O trabalho teve como objetivo avaliar o efeito de doses de nitrogênio sobre a qualidade fisiológica, física e nutricional de sementes de trigo (Triticum aestivum L.). O experimento foi realizado utilizando-se seis lotes de sementes de trigo produzidas sob diferentes doses de nitrogênio $\left(0,30,60,90,120\right.$ e $\left.150 \mathrm{~kg} \mathrm{ha}^{-1}\right)$. Utilizaram-se os testes de germinação, envelhecimento acelerado, condutividade elétrica, emergência em campo e lixiviação de potássio, e as características massa de mil sementes, massa do hectolitro, teores de potássio e nitrogênio total nas sementes, para inferir sobre a qualidade das sementes. O aumento das doses de N, na cultura do trigo, permite maior vigor das sementes submetidas ao armazenamento,

Palavras-chave: Triticum aestivum L., nitrogênio, vigor.

\section{Nitrogen fertilization and seed physiological quality of wheat}

\begin{abstract}
The nitrogen fertilization affects the amount of seed protein and therefore it is an important factor in the production of high quality seeds. This study aimed to evaluate the influence of six nitrogen concentrations on physiological quality of wheat seeds (Triticum aestivum L.). The experiment was carried out using six wheat seed lots derived from plants grown under different nitrogen doses $\left(0,30,60,90,120\right.$ e $\left.150 \mathrm{~kg} \mathrm{ha}^{-1}\right)$. The evaluation included germination test, accelerated aging, electrical conductivity, emergence in the field, weight of thousand seeds, hectolitre weight, determination of total potassium and total nitrogen and potassium leaching of the seeds. Increased doses of $\mathrm{N}$ in the wheat crop allows greater vigor of seeds submitted to storage, providing greater total nitrogen content in seeds and a reduction in the potassium leaching of seeds.
\end{abstract}

Key words: Triticum aestivum L., nitrogen, vigor.

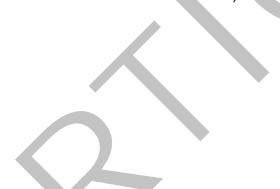

No Brasil, há interesse socioeconômico em aumentar a produção de trigo (Triticum aestivum L.), pois, além do atendimento à demanda nacional de grãos, seu cultivo fornece palhada para as culturas de verão, como soja e milho. Porém, todos os esforços no sentido de aumentar a produtividade da cultura, como melhoramento genético e uso de práticas culturais mais eficientes, poderão ser frustrados se o desempenho das sementes for fator limitante no processo produtivo.

Nos campos de produçáo de sementes, o uso de fertilizantes é mais comum do que em lavouras para produção de grãos, pois, as condiçôes do solo, no tocante à composição e disponibilidade de nutrientes para as plantas, influem na sua produçáo e qualidade, afetando a formação do embrião e dos órgãos de reserva, assim como a composição química e, consequentemente, o metabolismo e o vigor das sementes (Oliveira et al., 2006). O emprego de fórmulas equilibradas, contendo, fósforo e potássio, aliado à aplicação de nitrogênio, em dose e tempo certos, estimula a produçáo de sementes (Oliveira et al., 2003). Contudo, o número de experimentos relacionados especificamente com essa finalidade é limitado, de modo que o emprego de fertilizantes é feito com base nos resultados para as respectivas culturas destinadas ao consumo de gráos.

O vigor das sementes, que exprime seu nível de qualidade fisiológica, está relacionado com uma série de fatores como: condiçóes climáticas durante a maturação, condiçóes de armazenamento, tamanho das sementes, grau de injúria mecânica, tratamento químico das sementes e nutrição das plantas entre outros 
(Carvalho e Nakagawa, 2000; Meireles et al., 2009; Toledo et al., 2009).

A quantidade de $\mathrm{N}$ absorvido durante o ciclo da planta exerce influência importante no teor proteico das sementes. Kolchinski e Schuch (2004) relatam que, em cereais, as sínteses de proteína e de amido competem por fotossintetizados durante o período de enchimento de grãos e quando a necessidade de $\mathrm{N}$ para o rendimento é satisfeita, o $\mathrm{N}$ é usado para aumentar a concentraçáo de proteína. Desta forma, em carência de N, os fotossintetizados que seriam convertidos em proteínas são usados na síntese de carboidratos.

Como constituinte de biomoléculas na planta, o $\mathrm{N}$ pode afetar a qualidade das sementes. Trabalhos realizados com trigo têm mostrado a existência de correlaçáo positiva entre o teor de proteína e o vigor das sementes (Carvalho e Nakagawa, 1988). Segundo Kolchinski e Sснисн (2004), a disponibilidade de nutrientes influencia a composição química da semente, a formaçáo do embriáo e das estruturas de reserva e, consequentemente, o desempenho fisiológico da semente.

Trabalhos que objetivam relacionar a adubação e nutrição das plantas produtoras de sementes com a qualidade fisiológica das sementes são em número reduzido e os resultados nem sempre são concordantes. CARVAlHo et al. (2001), trabalhando com parcelamento e fontes de nitrogênio em feijão, verificaram que a adubação nitrogenada influenciou positivamente $\mathrm{o}$ vigor das sementes comerciais, não sendo o parcelamento e a fonte consistentes quanto aos seus efeitos sobre o vigor das sementes. Em aveia branca, Kolchinski e Schuch (2004) verificaram que a adubação em cobertura com doses de 0, 24, 48 e $73 \mathrm{~kg} \mathrm{ha}^{-1}$ de $\mathrm{N}$ não afetou o rendimento industrial e a qualidade fisiológica das sementes. Oliveira et al. (2003), estudando o efeito de fontes e doses de nitrogênio em feijão-vagem, observaram que as fontes influenciaram diferentemente o vigor e a germinação das sementes. Pode-se verificar, portanto, a necessidade da realizaçáo de mais estudos sobre a adubação/nutrição e qualidade fisiológica das sementes para melhor elucidar as necessidades em nutrientes de cada espécie e fazer recomendação de adubação para produção de sementes, visando também à qualidade fisiológica.

Objetivou-se neste trabalho avaliar o efeito de doses de nitrogênio sobre a qualidade fisiológica, física e nutricional de sementes de trigo.

O experimento de campo, para a produção das sementes, foi desenvolvido com irrigação por aspersão no período de maio a setembro de 2007 . A cultivar de trigo utilizada foi a BRS 254. Utilizou-se delineamento em blocos casualizados com quatro repetiçóes. Os tratamentos foram compostos por seis doses de nitrogênio, 0,30 , 60, 90, 120 e $150 \mathrm{~kg} \mathrm{ha}^{-1}$, aplicados na forma de ureia em cobertura por ocasiáo do início do perfilhamento. Cada parcela foi constituída por oito linhas com $5 \mathrm{~m}$ de comprimento espaçadas entre si em $0,184 \mathrm{~m}$. A área útil da parcela $\left(2,94 \mathrm{~m}^{2}\right)$ foi constituída pelas quatro linhas centrais, sendo eliminado $0,5 \mathrm{~m}$ em ambas as extremidades das linhas. As sementes foram colhidas e enviadas ao Laboratório de Análise de Sementes.

Para caracterizar os lotes quanto ao potencial fisiológico foram realizados os testes: teor de água, germinação, primeira contagem da germinação, envelhecimento acelerado, condutividade elétrica, emergência de plântulas em campo e lixiviação de potássio, além do teor de nitrogênio e do íon $\mathrm{K}^{+}$nas sementes, massa de mil sementes e massa do hectolitro.

O teor de água foi determinado pelo método padrão de estufa, a $105 \pm 3{ }^{\circ} \mathrm{C}$ durante 24 horas, com quatro repetiçôes de $5 \mathrm{~g}$ de sementes por lote, seguindo as instruçôes das Regras para Análise de Sementes (BrasiL, 1992). Os resultados foram expressos em porcentagem.

$\mathrm{O}$ teste de germinação foi feito com quatro repetiçōes contendo 50 sementes de cada lote, sẹndo distribuídas em rolo de papel Germitest, umedecido com volume de água 2,5 vezes a massa do substrato, e colocados em câmara de germinação a $20^{\circ} \mathrm{C}$. As avaliaçóes foram realizadas aos quatro e oito dias após a semeadura, de acordo com as recomendações das Regras para Análise de Sementes (Brasil, 1992).

primeira contagem da germinação foi realizada conjuntamente com o teste de germinação, avaliando-se o número de plântulas normais no quarto dia do teste. Os resultados foram expressos em porcentagem de plântulas normais.

No teste de envelhecimento acelerado, uma camada uniforme de sementes de cada lote foi distribuída sobre suportes com telas dentro de caixas de plástico tipo Gerbox, contendo $40 \mathrm{~mL}$ de água deionizada, e levadas para estufa incubadora, regulada a $43{ }^{\circ} \mathrm{C}$ durante 48 horas (Lima et al., 2006). Após o período de envelhecimento foi avaliado o teor de água das sementes, pelo método padrão de estufa e novo teste de germinação, sendo feita uma única avaliação aos quatro dias após a realização do teste (BRASIL, 1992).

$\mathrm{O}$ teste de condutividade elétrica foi feito com quatro repetiçóes de 50 sementes por lote, de acordo com o método proposto por LoEFFLER et al. (1988). As sementes foram pesadas (precisão de $0,01 \mathrm{~g}$ ) e colocadas em copos plásticos (diâmetro da base $6 \mathrm{~cm}$ ), nos quais foram adicionados $75 \mathrm{~mL}$ de água deionizada. As sementes imersas permaneceram em câmara BOD, a $25^{\circ} \mathrm{C}$ durante 18 horas. A condutividade elétrica da solução de imersão foi obtida por condutivímetro e expressa em $\mu$ mohs $\mathrm{cm}^{-1} \mathrm{~g}^{-1}$.

Para obtenção da emergência de plântulas em campo, a semeadura foi realizada na época recomendada para a cultura do trigo (15 de maio a $1 .^{\circ}$ de junho), em Argissolo Vermelho-Amarelo com textura argilosa, preparado com sulcos de $1 \mathrm{~m}$ linear, com profundidade uniforme e recomendada para a cultura utilizando-se quatro repetiçóes de cem sementes por lote, em delineamento em blocos 
casualizados. As avaliaçóes foram realizadas diariamente, a partir da primeira plântula emergida, até a obtenção de número constante. Os resultados foram expressos pela percentagem de emergência de plântulas e pelo índice de velocidade de emergência (IVE), calculado de acordo com Maguire (1962).

No teste de lixiviação de potássio, oito repetições de 50 sementes puras de cada lote foram colocadas em copos plásticos de $200 \mathrm{~mL}$, nos quais foram adicionados $75 \mathrm{~mL}$ de água deionizada e mantidos à temperatura de $25^{\circ} \mathrm{C}$ por 120 minutos. A determinação do potássio lixiviado foi realizada empregando-se o método de fotometria de chama. Os valores foram expressos em gramas de $\mathrm{K}^{+} \mathrm{kg}^{-1}$ de semente.

A massa de mil sementes foi determinada a partir de oito repetições de cem sementes (BRASIL, 1992) e os resultados foram expressos em gramas. A massa do hectolitro foi determinada utilizando balança apropriada e os resultados expressos em $\mathrm{kg} \mathrm{hL}^{-1}$.

Os dados foram submetidos à análise de variância e, detectadas diferenças, aplicaram-se análises de regressão, sendo os modelos matemáticos escolhidos de acordo com as equaçóes com melhores ajustes, confirmados pelos maiores valores dos coeficientes de determinação $\left(\mathrm{r}^{2}\right)$ e pela significância dos coeficientes de regressão $(\beta i)$ e do teste $\mathrm{F}$ da regressão, ambos considerando $\mathrm{p}<0,05$.

Os testes utilizados não detectaram diferenças significativas na qualidade fisiológica das sementes, na emergência e no índice de velocidade de emergência de plântulas de trigo oriundas de sementes produzidas sob diferentes doses de nitrogênio (Figura 1a,b), com exceção do teste de envelhecimento acelerado que detectou aumento na porcentagem de germinaçáo das sementes com a elevaçáo das doses de nitrogênio aplicadas. Resultados semelhantes também foram constatados por KOLCHINSKI e SCHUCH (2004) com aveia branca. Tais resultados sugerem que houve diferença na qualidade fisiológica das sementes; no entanto, essas diferenças foram sutis, tendo sido detectadas apenas em um teste que aplica condiçóes extremas, nas quais ocorrem alteraçôes no metabolismo, incluindo funcionalidade das membranas, síntese de proteínas e ácidos nucléicos e metabolismo do DNA. Esse teste, além de proporcionar envelhecimento das sementes, ocasiona atraso no processo germinativo, menor crescimento do embrião e aumento de suscetibilidade a estresses ambientais, levando eventualmente à perda de viabilidade (MAIA et al., 2007).

$\mathrm{O}$ aumento das doses de nitrogênio promoveu reduçáo na massa de mil sementes (MMS), na massa do hectolitro $(\mathrm{MH})$ (Figura 2a,b), na quantidade de potássio lixiviado (Figura 2e) e no aumento do teor de nitrogênio presente nas sementes (Figura 2c), mas não afetou a concentração de potássio nas sementes (Figura 2d). Os resultados de MMS e MH podem ser explicados pelo fato de as maiores doses de nitrogênio, aplicadas para a produção
-G(\%), $\hat{Y}=91,20 ; \circ \quad P C G(\%), \hat{Y}=62,87 ;-\operatorname{ENV}(\%), \hat{Y}=44,72+0,0735 x$; $\triangle \mathrm{COND}\left(\mu \mathrm{mhoscm}^{-1} \mathrm{~g}^{-1}\right), \hat{\mathrm{Y}}=29,24 ; \boldsymbol{U}(\%), \hat{\mathrm{Y}}=12,52$

(a)

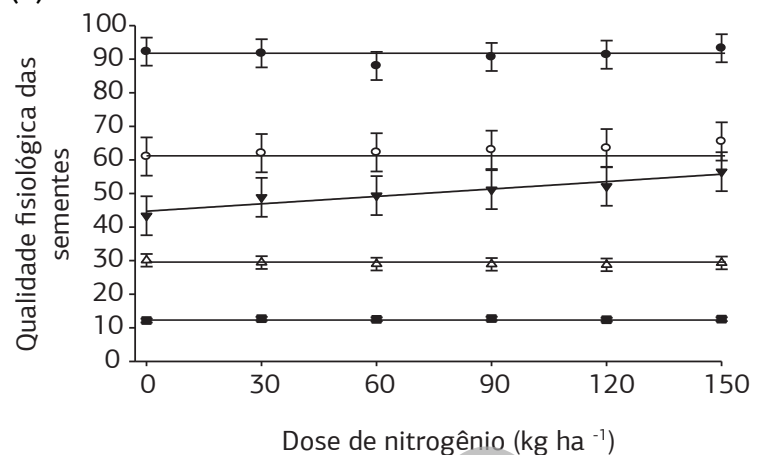

(b)

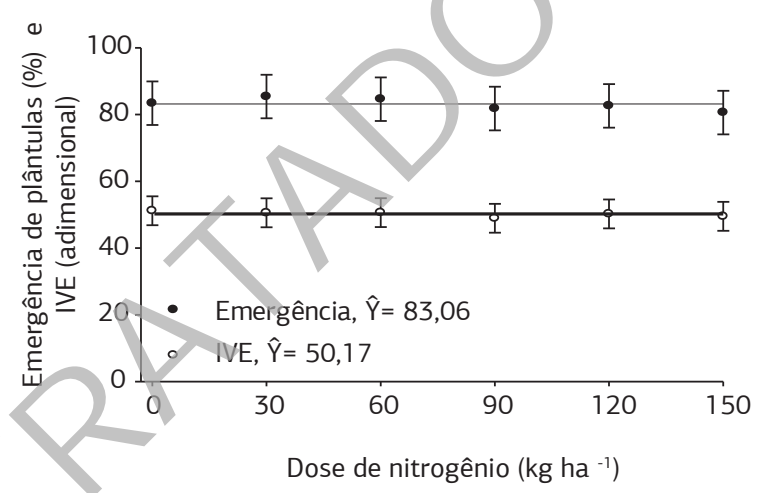

Figura 1. (a) Porcentagem de plântulas normais dos testes de germinação $[\mathrm{G}(\%)]$, primeira contagem da germinação [PCG(\%)], envelhecimento acelerado $[\mathrm{ENV}(\%)]$, condutividade elétrica [COND ( $\mu$ mhos $\mathrm{cm}^{-1} \mathrm{~g}^{-1}$ ) e umidade $[\mathrm{U}(\%)]$. (b) Emergência (\%) e Índice de Velocidade de Emergência (IVE) de plântulas de trigo oriundas de sementes produzidas sob diferentes doses de nitrogênio. Cada símbolo representa o valor médio de quatro repetiçóes ( \pm desvio-padrão).

das sementes, proporcionarem às plantas de trigo a produçáo de maior número de sementes por espigas, formando sementes de menor tamanho, pelo enchimento deficiente (CAZETtA et al., 2008) devido à competiçấo por fotoassimilados. Estas características relacionadas com a produtividade e com a qualidade dos grãos são parâmetros utilizados em experimentos agronômicos para a avaliaçáo de cultivares.

A redução da quantidade de potássio lixiviado das sementes com a elevação das doses de nitrogênio aplicadas deve estar relacionada com o teor de nitrogênio presente nas sementes. Provavelmente, esse processo ocorre porque a adubação nitrogenada interfere no conteúdo de proteína, podendo afetar a qualidade das sementes (LopezBellido et al., 2004), visto que as proteínas de reserva são hidrolisadas durante a germinação das sementes, para suprir com nitrogênio, enxofre e esqueletos de carbono o eixo embrionário e a plântula durante as fases iniciais de desenvolvimento (Imolesi et al., 2001). Portanto, a reduçâo da quantidade de proteína na semente pode ocasionar 

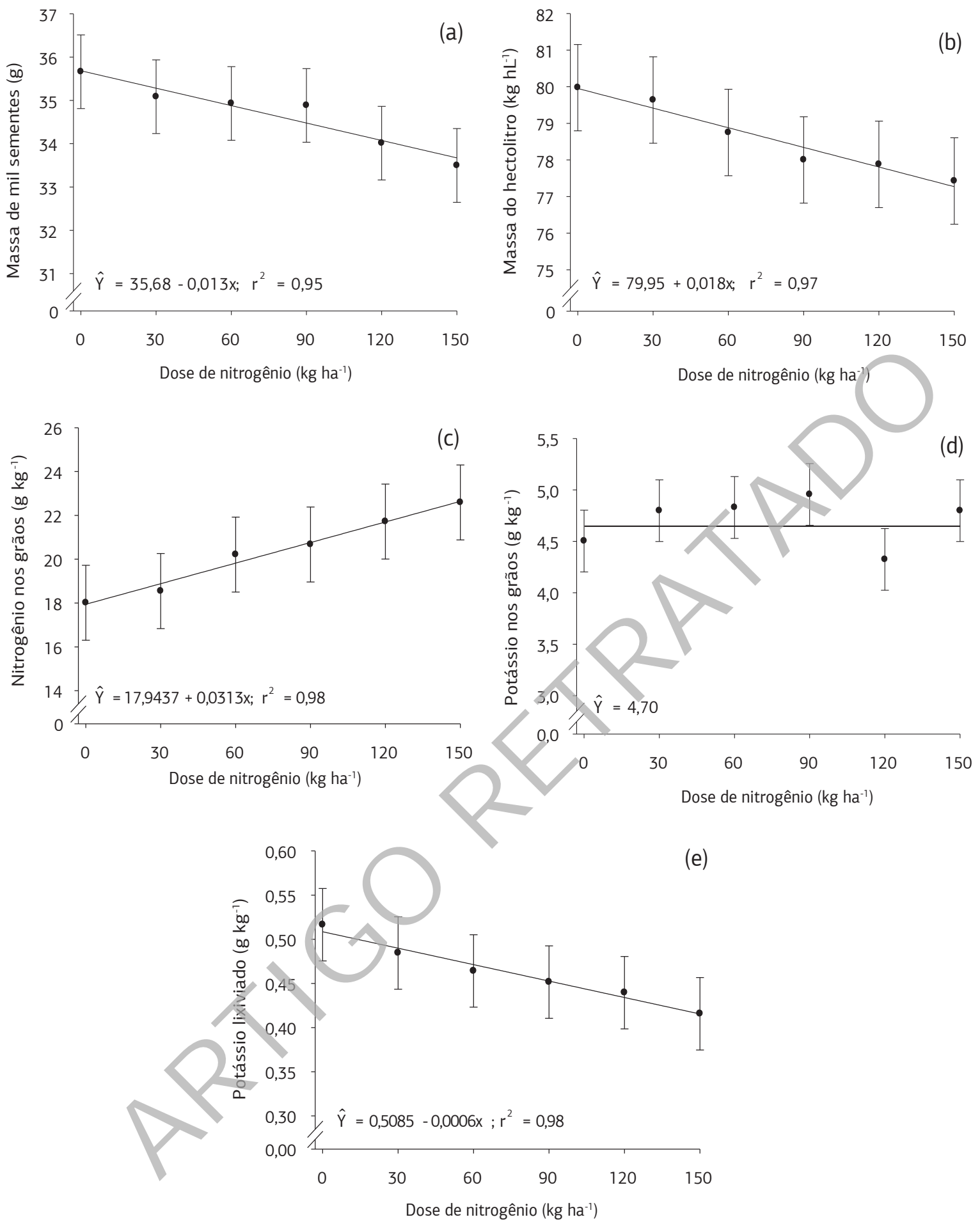

Figura 2. Massa de mil sementes (a), massa do hectolitro (b), concentração de nitrogênio (c) e potássio (d) e lixiviação de potássio (e) de sementes de trigo produzidas sob diferentes doses de nitrogênio. Cada símbolo representa o valor médio de quatro repetiçóes $( \pm$ desviopadrão).

deterioração mais rápida das sementes, proporcionando maior lixiviação de potássio.

O resultado náo significativo da concentração de potássio sugere que a lixiviação de potássio não esteve relacionada com a quantidade de potássio presente nas sementes. Por outro lado, esperava-se que, com a redução da MMS (tamanho) e MH (densidade), a entrada de água nas sementes fosse facilitada pelo menor tamanho da semente, acarretando maior lixiviação como sugere BECKER et al. (2000) e, no entanto, ocorreu o contrário, a lixiviação de potássio (Figura 2e) diminuiu, acompanhando a queda da MMS e da MH. 
$\mathrm{O}$ aumento das doses de $\mathrm{N}$, na cultura do trigo, permite maior vigor das sementes submetidas ao envelhecimento acelerado, proporciona maior teor de nitrogênio total nas sementes e redução na lixiviação de potássio das sementes e da massa de mil sementes e do hectolitro.

\section{REFERÊNCIAS}

BECKER, O.P.; MIGUEL, M.H.; MARCOS FILHO, J. Absorção de água e potencial fisiológico em sementes de soja de diferentes tamanhos. Scientia Agricola, v.57, p.671-675, 2000.

BRASIL. Ministério da Agricultura e Reforma Agrária. Regras para análise de sementes. Brasília, DNDV/CLAV, 1992. 365p.

CARVALHO, M.A.C.; ARF, O.; SÁ, M.E.; BUZETTI, S.; SANTOS, N.C.B.; BASSAN, D.A.Z. Produtividade e qualidade de sementes de feijoeiro (Phaseolus vulgaris L.) sob influência de parcelamentos e fontes de nitrogênio. Revista Brasileira de Ciência do Solo, v.25, p.617-624, 2001.

CARVALHO, N.M.; NAKAGAWA, J. Sementes: ciência, tecnologia e produção. 4.ed. Jaboticabal: Funep, 2000. 588p.

CARVALHO, N.M.; NAKAGAWA J. Sementes: ciência, tecnologia e produção. 3.ed. Campinas: Fundação Cargill, 1988. 424p.

CAZETTA, D.A.; ARF, O.; BUZETTI, S.; SÁ, M.E.; RODRIGUES, R.A.F. Desempenho de arroz de terras altas com aplicação de doses de nitrogênio em sucessão às culturas de cobertura do solo em sistema de plantio direto. Bragantia, v.67, p.471-479, 2008.

IMOLESI, A.S.; PINHO, E.V.R.V.; PINHO, R.G.V.; VIEIRA, M.D.G.G.C.; CORRÊA, R.S.B. Influência da adubação nitrogenada na qualidade fisiológica das sementes de milho. Ciência e Agrotecnologia, v.25, p.1119-1126, 2001.

KOLCHINSKI, E.M.; SCHUCH, L.O.B. Relaçôes entre a adubação nitrogenada e a qualidade de grãos e de sementes em aveia branca. Ciência Rural, v.34, p.379-383, 2004.
LIMA, T.C.; MEDINA, P.F; FANAN, S. Avaliação do vigor de sementes de trigo pelo teste de envelhecimento acelerado. Revista Brasileira de Sementes, v.28, p.106-113, 2006.

LOEFFLER, T. M.; TEKRONY, D. M.; EGLI, D. B. The bulk conductivity test as an indicator of soybean seed quality. Journal of Seed Technology, v.12, p.37-53, 1988.

LOPEZ-BELLIDO, R.J.; SHEPHERD, C.E.; BARRACLOUGH, P.B. Predicting post-anthesis $\mathrm{N}$ requirements of bread wheat with a Minolta SPAD meter. European Journal of Agronomy, v.20, p.313320, 2004.

MAGUIRE, J.B. Speed of germination-aid in selection and evaluation for seedling emergence vigor. Crop Science, v.2, p.176177, 1962.

MAIA, A.R.; LOPES, J.C. TEIXEIRA, C.O. Efeito do envelhecimento acelerado na avaliaçấ da qualidade fisiológica de sementes de trigo. Revista Brasileira de Sementes, v.31, p.678-684, 2007.

MEIRELES, R.C. SILVA; R.F.; ARAÚJO, E.F. REIS, L.S.; LYRA, G.B.; MARINHO, A.B. Influência do nitrogênio e das lâminas de irrigaçâ na qualidade fisiológica das sementes de mamoeiro. Revista Brasileira de Sementes, v.31, p.216-221, 2009.

OLIVEIRA, A.P.; ALVES, E.U.; BRUNO, R.L.A.; SADER, R., ALVES, A.U. Produção e qualidade fisiológica de sementes de coentro em funçáo de doses de nitrogênio. Revista Brasileira de Sementes, v.28 p.193-198, 2006.

OLIVEIRA, A.P.; PEREIRA, E.L.; BRUNO, R.L.A.; ALVES, E.U.; COSTA, R.F; LEAL, F.R.F. Produção e qualidade fisiológica de sementes de feijão-vagem em função de fontes e doses de nitrogênio. Revista Brasileira de Sementes, v.25, p.49-55, 2003.

TOLEDO, M.Z.; FONSECA, N.R.; CESAR, M.L.; SORATTO, R.P.; CAVARIANI, C.; CRUSCIOL, C.A.C. Qualidade fisiológica e armazenamento de sementes de feijão em função da aplicação tardia de nitrogênio em cobertura. Pesquisa Agropecuária Tropical, v.39, p.124-133, 2009. 